\title{
Penerapan Model Pembelajaran Discovery Learning untuk Meningkatkan Hasil Belajar IPA pada Siswa Kelas V
}

\author{
Marina Rizki Tri Cahyani \\ SD Muhammadiyah 8 Jagalan Surakarta \\ teccemarr@gmail.com
}

\section{Article History}

received 3/12/2020

revised $17 / 12 / 2020$

accepted $31 / 12 / 2020$

\begin{abstract}
The purpose of the study was to improve science learning outcomes in the symbiotic material. The research method is classroom action research (learning improvement) with two cycles, namely cycle I and cycle II. Data collection techniques using learning outcomes tests. The data analysis technique used is descriptive quantitative with presentile data analysis. Based on the improvement of learning cycle I and cycle II, the learning outcomes of cycle I can be presented which can achieve completeness as many as 19 students (66.00\%) with a class average of 71.1. Cycle II learning outcomes that can achieve completeness are 27 students (93.1\%) with a class average of 84.1. Judging from the percentage of completeness and the average value of increasing learning outcomes, it can be concluded that the use of the discovery learning model in the symbiotic material can significantly improve learning outcomes.
\end{abstract}

Keywords: learning outcomes, discovery learning, symbiosis

\begin{abstract}
Abstrak
Penelitian ini bertujuan untuk meningkatkan hasil belajar IPA pada materi simbiosis. Metode penelitian yang digunakan adalah penelitian tindakan kelas (peningkatan pembelajaran) dengan dua siklus yaitu siklus I dan siklus II. Teknik pengumpulan data menggunakan tes hasil belajar. Teknik analisis data yang digunakan adalah deskriptif kuantitatif dengan analisis data presentile. Berdasarkan peningkatan pembelajaran siklus I dan siklus II, dapat disajikan hasil belajar siklus I yang dapat mencapai ketuntasan sebanyak 19 siswa $(66,00 \%)$ dengan rata-rata kelas 71,1 . Hasil belajar siklus II yang dapat mencapai ketuntasan sebanyak 27 siswa $(93,1 \%)$ dengan rata-rata kelas 84,1 . Dilihat dari persentase ketuntasan dan nilai rata-rata peningkatan hasil belajar, dapat disimpulkan bahwa penggunaan model discovery learning pada materi simbiosis dapat meningkatkan hasil belajar secara signifikan.
\end{abstract}

Kata kunci: hasil belajar, discovery learning, symbiosis

Social, Humanities, and Education Studies (SHEs): Conference Series p-ISSN 2620-9284 https://jurnal.uns.ac.id/shes

e-ISSN 2620-9292 


\section{PENDAHULUAN}

Belajar merupakan perubahan dalam kepribadian yang diwujudkan dalam bentuk keterampilan (psikomotor), sikap (afektif) dan pengetahuan (Daryanto \& Rahardjo, 2012). Ranah pengetahuan berkaitan dengan aspek intelektual, ranah keterampilan berkaitan dengan keterampilan motorik, sedangkan ranah sikap berhubungan dengan sikap dan nilai yang diwujudkan dalam tingkah laku siswa (Sudjana, 2009). Pembelajaran pada kurikulum 2013 diharapkan dapat menuntun siswa untuk mencari tahu dan menekankan berpikir logis, sistematis, dan kreatif. Pendekatan pembelajaran berdasarkan pengamatan, pertanyaan, pengumpulan data, penalaran, dan penyajian hasilnya melalui pemanfaatan berbagai sumber belajar Error! Reference source not found.. Hasil belajar adalah pencapaian bentuk perubahan perilaku yang cenderung menetap dari ranah kognitif, afektif, dan psikomotorik dari proses belajar yang dilakukan dalam waktu tertentu (Haris \& Jihad, 2012).

Secara harfiah, IPA adalah ilmu pengetahuan tentang alam atau yang mempelajari peristiwa-peristiwa yang terjadi di alam (PattaBundu, 2006). Hakikat IImu Pengetahuan Alam (IPA) meliputi 3 aspek, yaitu produk, proses dan pengembangan sikap. Proses pembelajaran IPA pada tidak cukup dilaksanakan dengan penyampaian informasi yang berupa konsep, namun juga harus memahami proses terjadinya fenomena IPA dengan melakukan pengindraan melalui kegiatan demonstrasi dan eksperimen. Oleh karena itu, pembelajaran IPA semestinya dirancang sedemikian rupa agar peserta didik memperoleh kegiatan yang baik dan bermakna.

Proses pembelajaran yang dilakukan oleh guru sangat menentukan hasil dari tujuan pembelajaran. Pada pelajaran IPA, anak usia SD masih banyak kesulitan dalam memahami tentang masalah yang bersifat abstrak, karena anak SD cenderung lebih mudah memahami sesuatu yang bersifat konkrit atau nyata. Hal ini menyebabkan anak mengalami kesulitan dalam memahami materi pembelajaran, sehingga hasil belajar terhadap pelajaran IPA masih rendah.

Hasil ulangan harian dan observasi awal pada mata pelajaran IPA di Kelas V-A SD Muhammadiyah 8 Jagalan Surakarta menunjukkan bahwa dari 29 siswa, hanya 11 siswa yang berhasil mencapai KKM, sedangkan sisanya sejumlah 18 siswa belum berhasil mencapai KKM yang ditentukan. Data tersebut menunjukkan bahwa lebih dari $65 \%$ siswa kelas V-A SD Muhammadiyah 8 Jagalan Surakarta mengalami kesulitan atau menemui masalah dalam menguasai kompetensi dasar IPA. Banyak sekali faktor yang berpengaruh pada keberhasilan pendidikan. Guru saat ini haruslah senantiasa up to date terhadap perkembangan ilmu pedagogi, misalnya konsep teaching centered learning sudah tidak tepat dipraktikkan saat ini. Sudah saatnya pola teaching centered learning digeser menjadi student centered learning (Baswedan, dikutip dalam Chatib, 2019).

Rendahnya hasil belajar IPA yang rendah disebabkan berbagai faktor baik dari guru maupun siswa. Pertama, model pembelajaran yang digunakan guru belum memaksimalkan aktivitas belajar siswa untuk menemukan konsep materi secara mandiri sehingga siswa cenderung pasif. Kedua, pembelajaran IPA belum menggunakan media pembelajaran yang sesuai sehingga pemahaman siswa terhadap materi IPA kurang, sebagaimana yang disebutkan Piaget bahwa siswa usia SD masih dalam tahap berpikir konkrit/ belum abstrak sehingga sangat membutuhkan media agar materi yang disampaikan lebih mudah dipahami. Ketiga, pembelajaran IPA belum bersifat kontekstual sehingga siswa kurang termotivasi untuk belajar.

Peningkatan hasil belajar IPA siswa dicapai dengan model yang sesuai untuk melatihkan kegiatan-kegiatan ilmiah siswa, sehingga perlu adanya penerapan model pembelajaran yang mendukung siswa untuk melakukan aktivitas-aktivitas pembelajaran seperti berdiskusi, merumuskan masalah, membuat hipotesis, melaksanakan percobaan, dan mengomunikasikan hasil percobaan melalui presentasi. Salah satu model yang tepat untuk mendorong aktivitas belajar siswa dan dapat 
digunakan sebagai solusi permasalahan dalam kelas adalah belajar penemuan atau discovery learning.

Belajar penemuan memerlukan pengajuan pertanyaan-pertanyaan, permasalahan-permasalahan, atau situasi-situasi yang membingungkan untuk diselesaikan dan dorongan bagi para siswa untuk membuat tebakan-tebakan jawaban yang intuitif jika mereka tidak yakin. Discovery Learning mengacu pada penguasaan pengetahuan untuk diri sendiri yang diperoleh melalui proses mencari, mengolah, menelusuri, dan menyelidiki. Model pembelajaran penemuan menggunakan prinsip metode ilmiah sehingga dapat melatih siswa bekerja secara sistematis untuk menemukan pengetahuan baru maupun untuk menyelesaikan permasalahan Error! Reference source not found.. Haris \& Jihad (2012) menyatakan bahwa menemukan adalah bagian penting dalam pembelajaran karena dengan menemukan sesuatu yang siswa cari, daya ingat siswa lebih melekat.

Discovery learning memiliki kelebihan meningkatkan aktivitas siswa dan meningkatkan motivasi siswa untuk berpartisipasi aktif dalam pembelajaran (Coffey, 2009). Menurut Rowntree (dalam Chatib, 2019), discovery learning adalah strategi pembelajaran yang cenderung meminta siswa untuk melakukan observasi, eksperimen, atau tindakan ilmiah hingga mendapatkan kesimpulan dari tindakan tersebut. Sedangkan, penelitian Alex dan Olubusuyi (2013) menunjukkan bahwa kelas yang menggunakan pembelajaran discovery learning lebih unggul dalam perolehan skor setelah dilakukan pretes dan postest serta pengamatan aktivitas siswa dibandingkan dengan kelas kontrol yang menggunakan metode ceramah.

Model pembelajaran Discovery learning sesuai dengan karakteristik pembelajaran IPA karena terdapat kegiatan mengamati dan menyimpulkan sehingga siswa diajak untuk menemukan konsep. Dari uraian di atas, maka diharapkan melalui penerapan model discovery learning, hasil belajar IPA siswa kelas VA dapat meningkat.

\section{METODE}

Penelitian Tindakan Kelas (PTK) diterapkan di Kelas VA SD Muhammadiyah 8 Jagalan Surakarta Tahun Ajaran 2019/2020. Sekolah beralamat di Jalan Suryo 145 Jagalan, Jebres, Surakarta, Jawa Tengah. Subjek penelitian adalah siswa Kelas V-A SD Muhammadiyah 8 Jagalan Surakarta Tahun Ajaran 2019/2020 yang berjumlah 29 siswa, terdiri atas 11 laki-laki dan 18 perempuan.

Penelitian dilakukan dengan penerapan model pembelajaran discovery learning dengan secara bersiklus. Siklus pertama dilaksanakan melalui 4 tahap dimulai dari perencanaan hingga refleksi. Hasil dari refleksi pada siklus pertama digunakan sebagai acuan dalam perencanaan siklus kedua dan seterusnya sehingga target tercapai. Jenis data yang digunakan yaitu data kuantitatif berupa nilai hasil belajar siswa (Arikunto, 2009: 131). Data kuantitatif dianalisis dengan menggunakan teknik analisis deskriptif kuantitatif.

Penelitian dilakukan secara bertahap meliputi tahap persiapan, pelaksanaan, dan penyelesaian. Tahap persiapan meliputi observasi, identifikasi masalah, penentuan tindakan, penyusunan proposal, penyusunan instrumen penelitian, dan pengajuan perijinan penelitian dilaksanakan pada bulan Januari - Februari 2020. Tahap pelaksanaan meliputi semua kegiatan yang berlangsung di lapangan yaitu penerapan model discovery learning, pengambilan data, dan analisis data dilaksanakan dalam 2 siklus pada bulan Februari - Maret 2020. Siklus 1 dilaksanakan pada 10 Februari 2020, sedangkan siklus II dilaksanakan pada 2 Maret 2020.

\section{HASIL DAN PEMBAHASAN}

Penerapan model discovery learning pada pembelajaran IPA materi simbiosis di kelas VA SD Muhammadiyah 8 Jagalan Surakarta Tahun Ajaran 2019/2020 terbukti 
memberikan dampak positif dalam meningkatkan kualitas proses pembelajaran. Discovery learning mengajak siswa belajar dengan cara menemukan konsep materi secara mandiri melalui kegiatan merumuskan, membuat hipotesis, merancang percobaan, mengamati, melakukan percobaan, menganalisis, serta menyimpulkan yang terakomodasi dalam sintaks model discovery learning.

Materi pelajaran yang diajarkan pada siklus I yaitu macam-macam simbiosis beserta contohnya. Keterlaksanaan proses pembelajaran sudah sesuai dengan sintaks discovery learning serta dilakukan penilaian terhadap hasil belajar siswa. Data hasil tes dan observasi pada siklus I menunjukkan nilai ketuntasan hasil belajar mengalami peningkatan dibandingkan dengan pra siklus.

Siklus II merupakan tindak lanjut dari pelaksanaan tindakan siklus I yang belum mencapai target pencapaian. Pelaksanaan tindakan pada siklus II tidak berbeda jauh dengan proses pembelajaran pada siklus I namun mengalami beberapa perbaikan diantaranya: 1) Pembentukan kelompok dibuat secara heterogen dan diberitahukan sebelum pembelajaran. 2) Guru memulai pembelajaran dengan pendampingan yang baik, kemudian perlahan dilatih untuk mandiri. 3) Guru memberi pemahaman pada siswa bahwa kerjasama kelompok itu penting, guru akan melihat kelompok yang kompak dan memberi apresiasi. 4) Guru menuntun siswa untuk belajar membagi tugas dan bertanggung jawab dalam kelompok agar semua anggota kelompok paham dengan materi. 5) Guru membantu dalam menentukan rumusan/hal - hal yang ingin dipelajari. 6) Guru memberi tugas sebelumnya agar siswa melakukan pengamatan mandiri di lingkungan rumah. 7) Siswa mengamati objek nyata secara langsung yaitu lingkungan sekitar sekolah. 8) Manajemen kelas yang belum maksimal pada siklus I dimaksimalkan pada siklus II dengan cara guru lebih tegas dalam mengawasi setiap kelompok agar siswa lebih disiplin dan bertanggung jawab saat pembelajaran.

Selama proses pembelajaran siklus II juga dilakukan observasi dan penilaian hasil belajar siswa. Data hasil observasi pada siklus II menunjukkan capaian nilai ketuntasan hasil belajar siswa mengalami peningkatan dibandingkan dengan prasiklus dan siklus I. Berdasarkan penelitian tindakan kelas yang telah dilakukan, penerapan model discovery learning meningkatkan hasil belajar IPA siswa yang sesuai dengan beberapa penelitian yang sudah ada. Pembahasan untuk peningkatan hasil belajar yang terjadi setiap siklus ditunjukkan melalui tabel dan gambar berikut:

Tabel 1. Rekapitulasi Capaian KKM Hasil Belajar IPA Siswa Kelas V-A pada Prasiklus, Siklus I dan Siklus II

\begin{tabular}{|c|c|c|c|c|c|c|c|}
\hline \multirow[b]{2}{*}{ No } & \multirow[b]{2}{*}{ Nilai } & \multicolumn{2}{|c|}{ Pra Siklus } & \multicolumn{2}{|c|}{ Siklus I } & \multicolumn{2}{|c|}{ Siklus II } \\
\hline & & $\begin{array}{c}\text { Jml } \\
\text { Siswa }\end{array}$ & $\begin{array}{c}\text { Persen } \\
(\%)\end{array}$ & $\begin{array}{c}\text { Jml } \\
\text { Siswa }\end{array}$ & $\begin{array}{c}\text { Persen } \\
(\%)\end{array}$ & $\begin{array}{c}\text { Jml } \\
\text { Siswa }\end{array}$ & $\begin{array}{c}\text { Persen } \\
(\%)\end{array}$ \\
\hline 1 & Tuntas & 11 & 38 & 19 & 66 & 27 & 93 \\
\hline 2 & $\begin{array}{c}\text { Tdk } \\
\text { Tuntas }\end{array}$ & 18 & 62 & 10 & 34 & 2 & 7 \\
\hline \multicolumn{2}{|c|}{ Jumlah } & 29 & 100 & 29 & 100 & 29 & 100 \\
\hline $\begin{array}{l}\text { Nilai } \\
\text { Nilai } \\
\text { Rata }\end{array}$ & $\begin{array}{l}\text { ertinggi } \\
\text { erendah } \\
\text { rata }\end{array}$ & & & & & & \\
\hline
\end{tabular}




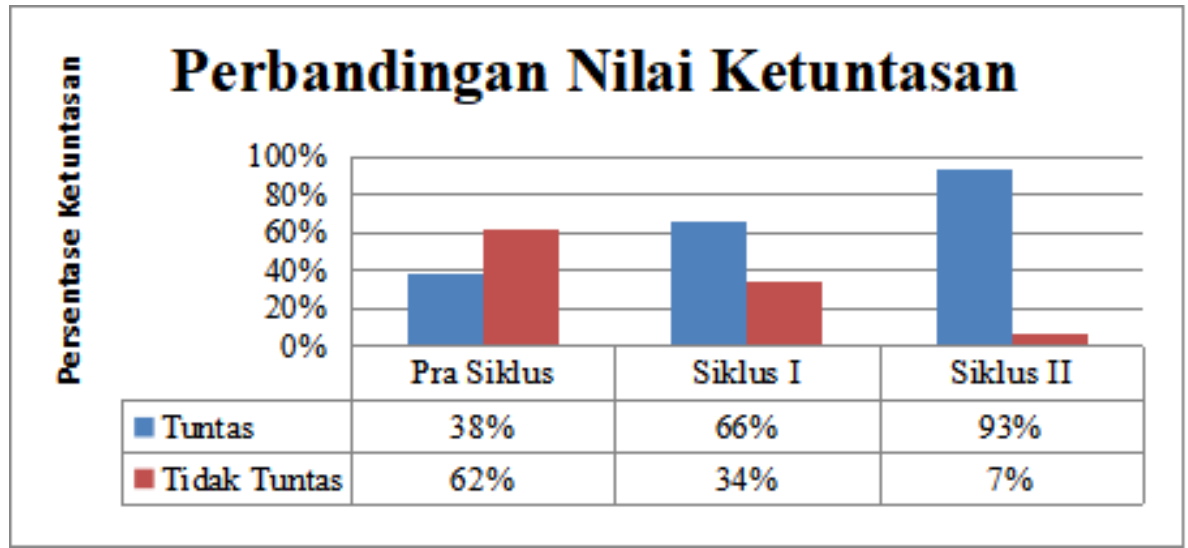

Gambar 1. Perbandingan Capaian Ketuntasan Hasil Belajar Pra Siklus, Siklus I dan Siklus II

Tabel 1 dan Gambar 1 menunjukkan bahwa hasil belajar IPA siswa siklus II mengalami peningkatan bila dibandingkan pada prasiklus dan siklus I. Data hasil observasi siklus II rata - rata nilai kelas mengalami peningkatan dari 65,2 menjadi 71,1 pada siklus I dan meningkat menjadi 84,1 pada siklus II. Capaian KKM hasil belajar IPA pada prasiklus adalah $38,00 \%$, meningkat menjadi $66,00 \%$ pada siklus I dan pada siklus II mencapai 93,00\%. Hasil analisis siklus II menunjukkan bahwa kegiatan pada siklus II berlangsung dengan baik dan terlaksana secara maksimal, peningkatan hasil belajar IPA siswa sudah menunjukkan hasil yang signifikan yakni sudah mencapai 93,00\% dari jumlah keseluruhan siswa mencapai KKM yang ditetapkan sekolah, maka diputuskan untuk menghentikan siklus.

Analisis data rata - rata nilai hasil belajar IPA secara keseluruhan sudah mengalami peningkatan dan mencapai target yang diinginkan pada siklus II. Perbandingan rata - rata nilai hasil belajar siswa prasiklus, siklus I, dan siklus II seperti pada Gambar 2.

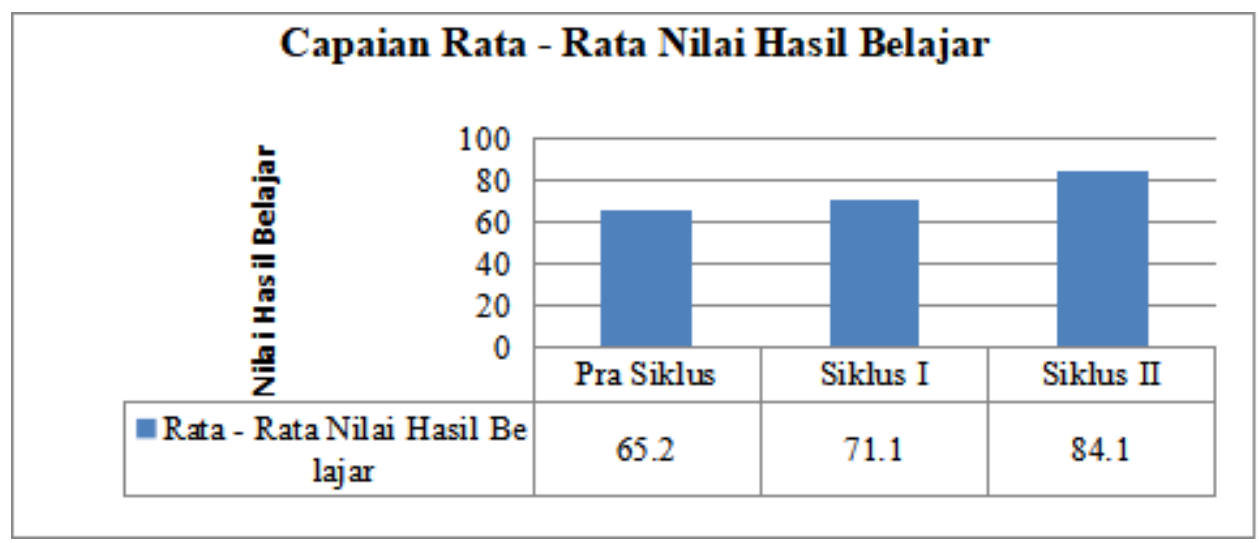

\section{Gambar 2. Rekapitulasi Capaian Rata-Rata Nilai Hasil Belajar Siswa Prasiklus, Siklus I dan Siklus II}

Discovery learning merupakan pembelajaran yang dilakukan dengan membangun fenomena dan pengetahuan melalui penyelidikan dengan prosedur sesuai metode ilmiah untuk menemukan suatu pemahaman dalam pembelajaran (Klahr \& Nigam, 2004). Kegiatan yang dilakukan dalam model Discovery meliputi 
mengeksplorasi, mendiskusikan, melakukan percobaan, menggambar rancangan dan hasil percobaan serta membangun pengetahuan. (Seel, 2012). Berdasarkan penelitian tindakan kelas yang telah dilakukan, penerapan model discovery learning meningkatkan hasil belajar IPA siswa yang sesuai dengan beberapa penelitian yang sudah ada.

Penerapan model discovery learning terbukti meningkatkan hasil belajar IPA siswa melalui kegiatan pengamatan, perumusan masalah, pengelompokan, pengajuan hipotesis, pembahasan, serta penarikan kesimpulan, sehingga mendorong siswa menemukan konsep-konsep dan prinsip materi melalui proses mentalnya sendiri selama proses pembelajaran berlangsung (Nbina, 2013). Discovery learning mengubah pembelajaran teachered centered menjadi pembelajaran student centered. Penelitian Loibi dan Rummel (2014) yang menyatakan fasilitator dalam pembelajaran berbasis discovery (penemuan) dan pemecahan masalah membantu siswa untuk membuat atau menemukan solusi dan konsep yang lebih baik.

Peran guru sebagai fasilitator dalam memberikan instruksi secara langsung kepada siswa saat melakukan kegiatan discovery (penemuan) memberikan dampak positif bagi siswa, kegiatan siswa lebih terarah sesuai dengan tujuan yang ingin dicapai dalam proses pembelajaran dan lebih efisien serta menghemat alokasi waktu. Fakta tersebut sesuai dengan pendapat Mayer (2004) yang menyatakan bahwa discovery learning dengan bantuan guru secara langsung sebagai fasilitator lebih efektif dibandingkan pure discovery tanpa bantuan. Peran siswa dalam Discovery Learning yaitu menerapkan konsep dan prinsip yang telah ditemukan dalam pembelajaran, memecahkan masalah sendiri (tanpa bantuan guru), menarik kesimpulan dari suatu persoalan, menjalin hubungan sosial, mendiskusikan persoalan dengan teman lain, dan menggunakan seumber belajar yang tersedia Error! Reference source not found.

Data persentase capaian setiap aspek aktivitas belajar menunjukkan bahwa pembelajaran menggunakan model discovery learning memberikan pengaruh positif terhadap aktivitas belajar siswa yang didukung oleh beberapa penelitian lain yaitu Alex dan Olubusuyi (2013) yang menunjukkan bahwa kelas yang menggunakan pembelajaran discovery learning unggul dalam pengamatan aktivitas siswa dibandingkan dengan kelas yang menggunakan metode ceramah. IImi (2012) dalam penelitiannya menyimpulkan bahwa discovery memberikan pengaruh positif terhadap keterampilan proses sains siswa.

Model discovery learning secara tidak langsung juga meningkatkan hasil belajar siswa karena siswa lebih mudah memahami konsep materi dengan kegiatan langsung dan memanfaatkan lingkungan sebagai sumber belajar, sesuai dengan penelitian Khanifah, Pukan, dan Sukaesih (2012) yang menunjukkan bahwa pembelajaran dengan pemanfaatan lingkungan sekolah dan kegiatan laboratorium sebagai sumber belajar meningkatkan hasil belajar pada tiap siklus tindakan kelas.

Hasil penelitian tindakan kelas yang dilakukan dalam 2 siklus mengalami peningkatan yang siginifikan. Perbandingan rekapitulasi capaian ketuntasan yaitu $38,00 \%$ pada pra siklus meningkat menjadi $66,00 \%$ pada siklus I dan terakhir $93,00 \%$ pada siklus II menunjukkan efektivitas penerapan model Discovery learning sehingga dapat disimpulkan bahwa penerapan model discovery learning dapat meningkatkan hasil belajar IPA siswa kelas V.

\section{SIMPULAN}

Berdasarkan perbaikan pembelajaran siklus I dan siklus II dapat disajikan hasil belajar siklus I yang dapat mencapai ketuntasan sebanyak 19 siswa (66\%) dengan rata-rata kelas 71,1 . Hasil belajar siklus II jumlah siswa yang dapat mencapai ketuntasan sebanyak 27 siswa (93\%) dengan rata-rata kelas 84,1 . Hasil penelitian menunjukkan bahwa penerapan model discovery learning pada materi simbiosis dapat 
meningkatkan hasil belajar siswa kelas VA SD Muhammadiyah 8 Jagalan Surakarta Tahun Ajaran 2019/2020 secara signifikan.

Discovery learning dapat dijadikan salah satu alternatif model pembelajaran yang digunakan di kelas, khususnya pada mata pelajaran IPA. Tahap-tahap dalam model penemuan sesuai dengan karakter mata pelajaran IPA yaitu lebih mengutamakan proses untuk menemukan pengetahuan baru. Discovery learning menunjukkan hasil yang lebih baik ketika objek yang digunakan dalam kegiatan pengamatan adalah objek nyata/ bukan sekadar gambar.

\section{DAFTAR PUSTAKA}

Alex, A. M., \& Olubusuyi, F. M. (2013). Guided-Discovery Learning Strategy and Senior School Students Performance in Mathematics in Ejigbo, Nigeria. Journal of Education and Practice, IV(12), 82-89.

Alfieri, L., Brooks, P. J., Aldrich, N. J., \& Tenenbaum, H. R. (2011). Does DiscoveryBased Instruction Enhance Learning? Journal of Educational Psychology , 103 (1), 1-18.

Budiastra, Ketut \& Rokiyah, Isti. (2019). Pembelajaran IPA di SD. Tangerang Selatan: Universitas Terbuka.

Bundu, Patta. (2006). Penilaian Keterampilan Proses dan Sikap Ilmiah dalam. Pembelajaran Sains di SD. Jakarta : Depdiknas

Chatib, Munif. (2019). Gurunya Manusia. Bandung: Kaifa.

Coffey, H. (2009). Discovery Learning. North Carolina: Learn INC The University of North Carolina.

Daryanto, \& Rahardjo, M. (2012). Model Pembelajaran Inovatif. Yogyakarta: Graha Media.

Haris, Abdul. Asep Jihad. (2012). Evaluasi Pembelajaran. Yogyakarta : Multi Pressindo.

Ilahi, M. T. (2012). Pembelajaran Discovery Strategy \& Mental Vocational Skill. Jogjakarta: DIVA Press.

IImi, A. N. (2012). Pengaruh Penerapan Metode Pembelajaran Guided Discovery terhadap Keterampilan Proses Sains Siswa Kelas X SMA Negeri 1 Teras Boyolali Tahun Pelajaran 2011/2012. Jurnal Pendidikan Biologi FKIP UNS, IV(2), 44-52.

Inhelder, B., \& Piaget, J. (1958). The Growth of Logical Thinking: From Childhood to Adolescence. New York: Basic Books, Inc.

Kemendikbud. (2013). Pengembangan Kurikulum 2013.

Khanifah, S., Pukan, K. K., \& Sukaesih, S. (2012). Pemanfaatan Lingkungan Sekolah sebagai Sumber Belajar untuk Meningkatkan Hasil Belajar Siswa. Unnes Journal of Biology Education, 1(1), 66-73.

Klahr, D., \& Nigam, M. (2004). The Equivalence of Learning Paths in Early Science Instruction: Effect of Direct Instruction and Discovery Learning. Psycological Science, XV(10), 661-667.

Nbina, J. B. (2013). The Relative Effectiveness of Guided Discovery and Demonstration Teaching Method on Achievement of Chemistry Students of Different levels of Scientific Literacy. Journal of Research in Education and Society, 1-8.

Schunk, D. H. (2012). Learning Theories: An Educational Perspective. New York: McGraw-Hill Companies.

Seel, N. M. (2012). Encyclopedia of the Science of Learning. In R. A. Lavine, Guided Discovery Learning (pp. 1402-1403). United States: Springer US.

Sudjana, N. (2009). Penilaian Hasil Proses Belajar Mengajar. Bandung: Remaja Rosdakarya. 